\title{
Analisis Perbandingan Penggunaan Celebrity Endorser Dan Typical-Person Endorser Iklan Televisi Dan Pengaruhnya Terhadap Brand Image Produk Shampo Clear
}

\author{
Tri Yunianto \\ Universitas Muhammadiyah Purwokerto \\ Arini Hidayah \\ Univeritas Muhammadiyah Purwokerto
}

\begin{abstract}
This study aims to determine the effects difference and typical celebrity endorser endorser in the ad-person sampho Clear and determine the effect of typical celebrity endorser-person and endorser of the brand image of products sampho Clear. This study is a survey with a population of $m$ students Muhammadiyah University of Navan user and Clear shampoo sample of 97 respondents. Data analysis using independent sample t test analysis, multiple linear regression analysis with $t$ test and $F$ test.

The results showed that there are differences in usage and the typical endorser Celebrity endorsers in advertising-person sampho Clear. Based on t test results obtained for 2.976 t count bigger than $t$ table 1.653. celebrity endorser significant effect on brand image Clear shampoo brand. Value of $6.041 t$ count bigger than $t$ table 1.987. typical-person endorser significant effect on brand image Clear shampoo brand. Value of $3.417 t$ count bigger than t table 1.987.
\end{abstract}

Keywords: Celebrity endorsers, Typical-Person endorser, Brand Image

\section{PENDAHULUAN}

Persaingan bisnis dalam era globalisasi semakin dinamis, kompleks, dan serba tidak pasti, menyebabkan adanya peluang dan tantangan. Era globalisasi menuntut setiap perusahaan untuk selalu mendapatkan cara terbaik guna merebut dan mempertahankan pangsa pasar. Untuk itu, setiap perusahaan harus berusaha menarik perhatian (calon) konsumen melalui pemberian informasi tentang produk. Pemberian informasi dapat dilakukan melalui packaging, brosur, peragaan, ataupun kunjungan salesman atau salesgirl. Namun demikian, iklan masih dianggap paling efektif. Banyak perusahaan yang memanfaatkan media ini sebagai sarana mempengaruhi konsumen untuk melakukan pembelian terhadap produk yang diiklankan.

Iklan merupakan salah satu alat bauran promosi yang digunakan sebagai alat pengantar pesan untuk membentuk sikap konsumen. Agar penyampaian pesan dapat diterima oleh konsumen dengan baik maka dibutuhkan media yang tepat. Berkembangnya media informasi di Indonesia menyebabkan banyaknya iklan yang membanjiri media. Media yang digunakan adalah televisi, radio, majalah atau surat kabar, dan lain-lain. Pengiklanan di media televise hingga kini masih dianggap cara paling efektif dalam mempromosikan produk terutama di Indonesia yang masyarakatnya masih brand minded dimana mereka yang pernah muncul di iklan di televisi lebih digemari dalam beriklan agar dapat menarik perhatian konsumen dan menciptakan preferensi terhadap merek. Salah satu cara kreatif dalam beriklan adalah menggunakan endorser.

Sosok endorser dapat berasal dari kalangan selebriti dan orang biasa/non selebriti. Endorser sebagai opinion leader yang menyampaikan pesan hingga sampai ke konsumen mengenai merek produk. Opinion Leader berperan dalam memberikan informasi pada orang lain, pelaku persuasi, dan pemberi informasi. Perusahaan harus memilih endorser yang cocok dan untuk menyampaikan pesan iklan yang diinginkan kepada target audience, 
sehingga pesan tersebut sampai kepada konsumen yang dapat membentuk opini, dan mereka akan meneruskan opini tersebut sesuai persepsi masing-masing, dengan demikian diharapkan akan bertambahnya kesadaran terhadap produk.

Pemakaian selebriti pendukung (celebrity endorser) harus melalui beberapa pertimbangan, diantaranya adalah tingkat popularitas selebriti yang dapat mewakili karakter produk yang sedang diiklankan (Royan, 2004:7). Selebriti adalah sebagai sumber iklan atau informasi tentang merek dan atribut produk yang menyenangkan, meyakinkan dan menarik perhatian masyarakat umum. Memanfaatkan selebriti sebagai endorser dirasa memang lebih mudah mempengaruhi psikologis konsumsi konsumen. Penggunaan selebriti dalam suatu iklan melibatkan daya tarik dan kredibilitas yang merupakan keunikan tersendiri (Sebayang dan Siahaan, 2008:118).

Melalui penggunaan celebrity endorser, pemasar sekaligus dapat melakukan pembeda dengan produk - produk kompetitor yang ada di pasar. Basis pembedaan ini sangat penting karena basis pembeda ini akan digunakan konsumen untuk memilih dari berbagai macam produk yang ditawarkan produsen. Cara lain yang dapat dilakukan untuk menekankan basis pembeda adalah melalui brand association. Menurut Durianto (2001), brand association adalah segala kesan yang muncul dibenak seseorang yang terkait dengan ingatannya mengenai suatu merek. Dengan demikian perusahaan harus bias membangun asosiasi pada konsumen, sehingga membuat konsumen selalu mengingat sebuah merek dari asosiasi yang diciptakan oleh perusahaan karena medan pertempuran adalah dibenak konsumen.

Banyaknya merek yang bermain di dalam pasar produk shampo membuat persaingan pasar semakin seru. Salah satu produk shampoo yang mempunyai brand terkenal adalah sampho Clear. Clear mencoba terus melakukan perluasan pasar dengan strategi iklan yang intensif di layar televisi. Banyak variasi klip iklan yang ditayangkan baik menggunakan selebriti maupun bintang iklan biasa. Selebriti yang menjadi bintang iklan produk Clear salah satunya adalah Agnes Monica dan Ronaldo.

Penggunaan Celebrity Endorser dan Typical-Person Endorser pada iklan produk sampho Clear tersebut menarik untuk diteliti sehingga peneliti mengambil judul penelitian "Analisis Perbandingan Penggunaan Celebrity Endorser dan Typical-Person Endorser Iklan Televisi dan Pengaruhnya terhadap Brand Image Produk Shampo Clear".

\section{TINJAUAN PUSTAKA / LITERATUR}

Pemasaran adalah proses sosial dan manajerial yang seseorang atau kelompok memperoleh apa yang dibutuhkan melalui penciptaan dan pertukaran nilai barang dan jasa. The American Marketing Association mendefinisikan pemasaran sebagai proses perencanaan dan pelaksanaan konsepsi, penetapan harga, promosi dan distribusi ide, barang dan jasa untuk menciptakan pertukaran yang memuaskan tujuan individu dan organisasi (Kotler dan Keller, 2008).

Pemasaran merupakan salah satu faktor penting yang harus dilakukan oleh pengusaha dalam usahanya mempertahankan hidup perusahaannya untuk berkembang dan mendapatkan laba. Sejak orang mengenal kegiatan pemasaran telah banyak definisi pemasaran yang dikemukakan, definisi itu tampaknya berbeda satu sama lain tetapi mempunyai arti yang sama dikemukakan definisi pemasaran adalah sistem keseluruhan dari kegiatan usaha yang ditujukan merencanakan, menentukan harga, mempromosikan serta mendistribusikan barang dan jasa yang dapat memuaskan kepada pembeli yang ada maupun pembeli yang potensial (Swasta dan Handoko, 2000).

Periklanan merupakan cara menjual melalui penyebaran informasi kepada konsumen, baik konsumen potensial maupun pelanggan (Jefkins, 1996 dalam Hapsari, 2008). Sedangkan menurut Kotler (2001), periklanan adalah segala biaya yang harus dikeluarkan sponsor untuk melakukan presentasi dan promosi non-pribadi dalam bentuk gagasan, barang atau jasa.

Periklanan merupakan salah satu bentuk promosi yang paling dikenal, karena daya jangkaunya yang luas. Iklan yang disenangi konsumen terlihat menciptakan sikap merek 
yang positif dan keinginan untuk membeli yang lebih ketimbang iklan yang tidak mereka sukai. (Peter \& Olson, 2000)

Tujuan periklanan merupakan tugas komunikasi tertentu yang harus dilakukan dengan audiens sasaran tertentu selama periode waktu tertentu. Tujuan periklanan dapat digolongkan menurut keperluan utamanya, (Kotler , 2001) meliputi :

1. Periklanan Informatif

Yaitu periklanan yang digunakan untuk memberi informasi kepada konsumen mengenai suatu produk atau kelengkapan baru atau untuk membangun permintaan awal.

2. Periklanan Persuasif

Yaitu periklanan yang digunakan untuk membangun permintaan selektif akan suatu merek dengan cara meyakinkan konsumen bahwa merek tersebut adalah merek terbaik di kelasnya.

3. Periklanan Pengingat

Yaitu iklan yang digunakan untuk menjaga agar konsumen tetap berpikir mengenai suatu produk.

Menurut Tjiptono (2002), iklan adalah bentuk komunikasi tidak langsung yang didasari pada informasi tentang keunggulan atau keuntungan suatu produk yang disusun sedemikian rupa sehingga menimbulkan rasa menyenangkan yang akan mengubah pikiran seseorang untuk melakukan pembelian.

Fungsi utama iklan ada empat yang antara lain :

1. Informing

Yaitu menginformasikan khalayak mengenai seluk beluk produk;

2. Persuating

Yaitu mempengaruhi khalayak untuk membeli;

3. Reminding

Yaitu menyebarkan informasi yang telah diterima khalayak;

4. Entertainment

Yaitu menciptakan suasana yang menyenangkan sewaktu khalayak menerima dan membaca informasi.

Endorser yaitu orang atau karakter yang muncul dalam iklan untuk mengkomunikasikan produk perusahaan baik itu selebritis, tokoh masyarakat, publik figure atau bahkan orang biasa yang dapat mempengaruhi pikiran konsumen sebagai preferensi dalam melakukan keputusan pembelian (Engel, Black Well \& Miniard, 1990). Endorser juga diartikan sebagai orang yang dipilih mewakili imej sebuah produk (product image). Biasanya dari kalangan tokoh masyarakat memiliki karakter menonjol dan daya tarik yang kuat (Hardiman, 2006).

Shimp (2003) mendefinisikan celebrity endorser adalah seorang pribadi baik itu aktor, artis maupun atlit yang dikenal masyarakat dan menjadi pujaan, karena prestasinya di suatu bidang dan digunakan dalam menyampaikan pesan iklan yang dimaksudkan untuk menarik perhatian sehingga mempengaruhi konsumen sasaran.

Saat ini kebanyakan perusahaan menggunakan selebriti dibanding orang biasa untuk mengiklankan produknya karena selebriti memilki atribut kesohoran, kecantikan, keberanian, prestasi, jiwa olahraga (athleticisme), keanggunan, kekuasaan/kekuatan, dan daya tarik seksualnya sehingga sering mewakili daya tarik yang diinginkan perusahaan untuk mengiklankan produknya dan dijadikan pemikat yang ampuh bagi calon konsumen (Suyanto, 2005).

Typical-person endorser bintang iklan yang bukan artis atau orang yang tidak terkenal. Pemasar memilih typical-person endorser untuk mendukung ikaln, dengan alasan : Typical-person endorser biasanya digunakan sebagai bentuk promosi testimonial untuk meraih kepercayaan konsumen. Typical-person endorser dapat lebih diakrabi oleh konsumen karena mereka merasa memiliki kesamaan konsep diri yang actual (actualself concept), nilai-nilai yang dianut, kepribadian, gaya hidup (life styles), karakter demografis, dan sebagainya.

"A brand is an identifiable entity that makes specific promises of value" (Dolak, 2004). Merek merupakan hal yang sangat penting bagi produsen maupun konsumen. Merek bukan 
hanya simbol yang dipakai untuk mengidentifikasi produk atau perusahaan. Saat ini peranan atau fungsi dari suatu merek (brand) bukan hanya sebagai pembeda dari produk yang dihasilkan oleh produsen yang satu dengan produsen yang lainnya, namun merek merupakan penentu dalam menghasilkan suatu competitive advantages. Konsumen saat ini memandang merek atau brand sebagai salah satu hal yang sangat penting dalam melakukan keputusan pembelian, merek merupakan suatu nilai tambah (value) bagi suatu produk.

Berdasarkan kerangka diatas, maka penulis mengemukakan suatu hipotesis untuk identifikasi masalah dan tujuan penelitian sebagai berikut :

1. Terdapat perbedaan penggunaan Celebrity Endorser dan Typical-Person Enı r pada Iklan sampho Clear.

2. Terdapat pengaruh Celebrity Endorser terhadap Brand Image produk sampho Clear

3. Terdapat pengaruh Typical-Person Endorser terhadap Brand Image produk sampho Clear.

\section{METODOLOGI PENELITIAN}

\section{Populasi dan sampel}

Populasi penelitian ini adalah mahasiswa Universitas Muhammadiyah Purwokerto pengguna shampoo Clear. Teknik pengambilan sampel secara non probabilitas yang digunakan dalam penelitian ini adalah pengambilan sampel secara purposive sampling, yaitu pengambilan sampel yang didasarkan pada pertimbangan untuk menyesuaikan dengan kriteria penelitian agar dapat meningkatkan ketepatan sampel (Arikunto, 2002). Kriteria pengambilan sampel dalam penelitian ini adalah :

1. Mahasiswa UMP yang pernah menggunakan shampoo Clear

2. Mahasiswa UMP yang masih aktif.

\section{Definisi Operasional Variabel}

\section{Celebrity endorser}

Celebrity endorser adalah seorang pribadi baik itu aktor, artis maupun atlit yang dikenal masyarakat dan menjadi pujaan, karena prestasinya di suatu bidang dan digunakan dalam menyampaikan pesan iklan yang dimaksudkan untuk menarik perhatian sehingga mempengaruhi konsumen sasaran (Shimp, 2003). Indikator variabel ini adalah :

a. Bintang iklan menyampaikan pengetahuan dan pengalamannya memakai produk

b. Bintang iklan Shampoo Clear memiliki keterampilan dalam menyampaikan pesan iklan

c. Bintang iklan jujur dalam menyampaikan keunggulan produk

d. Bintang iklan memiliki penampilan yang menarik

e. Penampilan Bintang iklan ketika membintangi iklan sesuai dengan pesan iklan yang disampaikan

f. Bintang iklan memiliki kesamaan karakter dengan para konsumen dalam hal umur

g. Karakter bintang iklan unik dan menarik

h. Informasi yang diberikan menarik minat beli konsumen

i. Bintang iklan mampu menunjukan simpatik kepada konsumen.

2. Typical-Person Endorser

Typical-person endorser bintang iklan yang bukan artis atau orang yang tidak terkenal. Indikator variabel ini adalah :

a. Bintang iklan menyampaikan pengetahuan dan pengalamannya memakai produk

b. Bintang iklan Shampoo Clear memiliki keterampilan dalam menyampaikan pesan iklan

c. Bintang iklan jujur dalam menyampaikan keunggulan produk

d. Bintang iklan memiliki penampilan yang menarik

e. Penampilan Bintang iklan ketika membintangi iklan sesuai dengan pesan iklan yang sampaikan

f. Bintang iklan memiliki kesamaan karakter dengan para konsumen dalam hal umur

g. Karakter bintang iklan unik dan menarik 
h. Informasi yang diberikan menarik minat beli konsumenBintang iklan mampu menunjukan simpatik kepada konsumen.

\section{Brand Image}

Brand image adalah asosiasi yang muncul di benak konsumen ketika mengingat sebuah merek tertentu. Indikator variabel ini adalah :
a. Kredibilitas Bintang iklan dalam membintangi iklan Shampoo Clear mempengaruhi persepsi konsumen
b. Daya tarik Bintang iklan dalam membintangi iklan Shampoo Clear mempengaruhi persepsi konsumen
c. Kecocokan Bintang iklan dalam membintangi iklan Shampoo Clear mempengaruhi persepsi konsumen
d. Merek lebih terkenal dibanding merek lain
e. Merek meningkatkan prestise atau harga diri
f. Merek didukung oleh teknologi yang lebih tinggi
g. Merek memberikan pelayanan yang lebih maksimal
h. Mementingkan kebutuhan konsumen

\section{Alat analisis yang digunakan}

Alat analisis yang digunakan dalam penelitian ini adalah uji regresi linear berganda, dengan persamaan sebagai berikut:

$$
\begin{aligned}
& \text { Keterangan : } \\
& \mathrm{Y}=\text { brand image } \\
& \mathrm{a}=\text { Konstanta } \\
& \mathrm{b}_{1}-\mathrm{b}_{2}=\text { Koefisien regresi } \\
& \mathrm{X}_{1}=\text { celebrity endorser } \\
& \mathrm{X}_{2}=\text { typical-person endorser } \\
& \mathrm{e}=\text { error }
\end{aligned}
$$

\section{HASIL DAN PEMBAHASAN}

\section{Pengujian Hipotesis dan Pembahasan}

Hasil penelitian ini menunjukkan bahwa pengujian validitas dan reliabilitas serja uji asumsi klasik model regresi sudah terbebas dari permasalahan normalitas, multikolinearitas, autokrelasi dan heteroskedastisitas. Dengan demikian model regresi sudah tepat digunakan dalam pengujian hipotesis dalam penelitian ini.

\section{Tabel 1. Hasil olahan data Regresi Berganda}

Coefficients

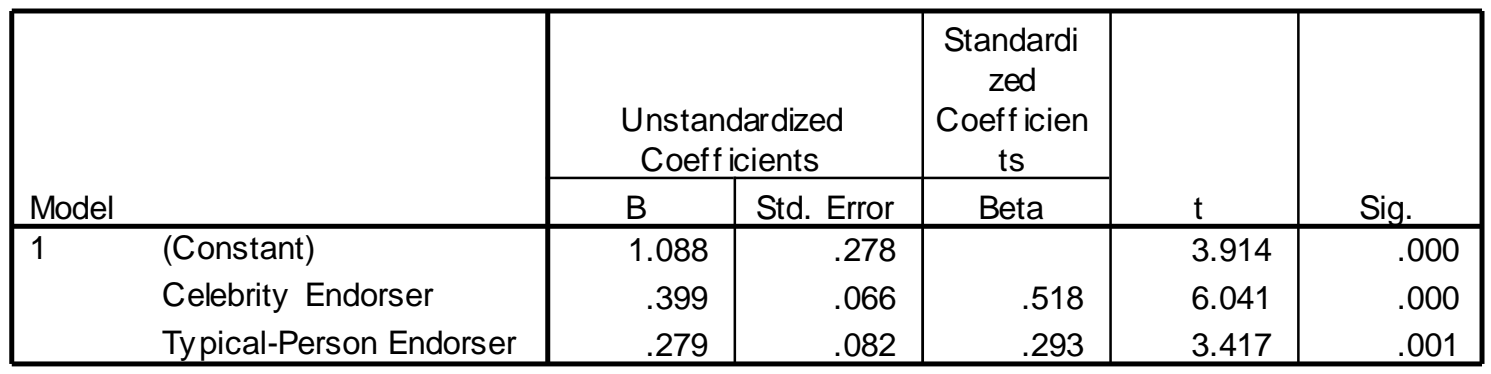

a. Dependent Variable: Brand Image

Berdasarkan hasil pada Tabel tersebut, maka dapat dibuat persamaan regresi sebagai berikut:

$Y=1,088+0,399 X_{1}+0,279 X_{1}+e$ 
Persamaan tersebut dapat dijabarkan sebagai berikut:

bo $=51,088$ artinya bahwa Brand Image shampoo merek Clear meningkat sebesar 1,088 skala apabila tidak dipengaruhi oleh variabel Celebrity Endorser dan TypicalPerson Endorser.

$\mathrm{b}_{1}=0,399$ artinya bahwa Brand Image shampoo merek Clear akan meningkat sebesar 0,399 satuan bila variabel Celebrity Endorser meningkat satu satuan dengan asumsi bahwa variabel Typical-Person Endorser bernilai konstan.

$\mathrm{b}_{2}=0,279$ artinya bahwa Brand Image shampoo merek Clear akan meningkat sebesar 0,279 satuan bila variabel Typical-Person Endorser meningkat satu satuan dengan asumsi bahwa variabel Celebrity Endorser bernilai konstan.

\section{Pengujian Hipotesis}

Untuk mengetahui pengaruh variabel independen Celebrity Endorser dan TypicalPerson Endorser terhadap Brand Image shampoo merek Clear, menggunakan uji t. Hasil uji t dapat dilihat dalam Tabel 1. Variabel Celebrity Endorser, Berdasarkan analisis Uji t pada Tabel 1 dapat menunjukkan nilai t hitung untuk variabel Celebrity Endorser 6,041. Nilai t hitung ini kemudian dibandingkan dengan nilai t tabel pada taraf signifikansi $95 \%$ dengan df 89, yaitu 1,987, berarti nilai t hitung lebih besar dari t tabel, maka Ho ditolak dan Ha diterima. Dengan demikian Celebrity Endorser berpengaruh signifikan terhadap Brand Image shampoo merek Clear.

Variabel Typical-Person Endorser, Berdasarkan analisis Uji t pada Tabel 1 dapat menunjukkan nilai $t$ hitung untuk variabel Typical-Person Endorser sebesar 3,417. Nilai $t$ hitung ini kemudian dibandingkan dengan nilai t tabel pada taraf signifikansi 95\% dengan df 89 , yaitu 1,987 , berarti nilai t hitung lebih besar dari t tabel, maka Ho ditolak dan Ha diterima. Dengan demikian Typical-Person Endorser berpengaruh signifikan terhadap Brand Image shampoo merek Clear.

Untuk menguji pengaruh variabel Celebrity Endorser dan Typical-Person Endorser terhadap Brand Image shampoo merek Clear secara keseluruhan digunakan Uji F yang diperoleh dari analisis regresi ganda sebagai berikut:

\section{Tabel 2. Hasil Uji F}

ANOVA

\begin{tabular}{|c|c|c|c|c|c|c|}
\hline \multicolumn{2}{|c|}{ Model } & $\begin{array}{l}\text { Sum of } \\
\text { Squares }\end{array}$ & $d f$ & Mean Square & $\mathrm{F}$ & Sig. \\
\hline \multirow[t]{3}{*}{1} & Regression & 7.672 & 2 & 3.836 & 44.981 & $.000^{a}$ \\
\hline & Residual & 7.590 & 89 & 8.528E-02 & & \\
\hline & Total & 15.262 & 91 & & & \\
\hline
\end{tabular}

a. Predictors: (Constant), Ty pical-Person Endorser, Celebrity Endorser

b. Dependent Variable: Brand Image

Berdasarkan hasil Uji $\mathrm{F}$ diperoleh $\mathrm{F}$ hitung sebesar 44,981 lebih besar dari $\mathrm{F}$ tabel pada taraf signifikan $95 \%$ dengan df $(89 ; 2)$ yaitu sebesar 3,098 , berarti $F$ hitung lebih besar dari $\mathrm{F}$ tabel $(44,981>3,099)$, maka Ho ditolak dan Ha diterima. Dengan demikian Celebrity Endorser dan Typical-Person Endorser secara simultan mempunyai pengaruh yang signifikan terhadap loy Brand Image shampoo merek Clear.

Untuk mengetahui besarnya kontribusi pengaruh Celebrity Endorser dan TypicalPerson Endorser terhadap Brand Image shampoo merek Clear dapat dilihat dari hasil uji determinasi $\left(\right.$ Adjusted $\mathrm{R}^{2}$ ). Hasil uji determinasi dapat dilihat pada Tabel 3 berikut ini. 
Tabel 3. Hasil uji $\mathbf{R}^{2}$

Model Summary

\begin{tabular}{|l|r|r|r|r|}
\hline Model & $\mathrm{R}$ & $\mathrm{R}$ Square & $\begin{array}{c}\text { Adjusted } \\
\text { R Square }\end{array}$ & $\begin{array}{r}\text { Std. Error of } \\
\text { the Estimate }\end{array}$ \\
\hline 1 & $.709^{\mathrm{a}}$ & .503 & .492 & .2920 \\
\hline
\end{tabular}

a. Predictors: (Constant), Ty pical-Person Endorser, Celebrity Endorser

b. Dependent Variable: Brand Image

Berdasarkan hasil uji determinasi dapat diperoleh nilai Adjusted $R$ square sebesar 0,492 (49,2\%). Berarti Brand Image shampoo merek Clear dipengaruhi oleh Celebrity Endorser dan Typical-Person Endorser sebesar 49,2\%, sedangkan sisanya 50,8\% dipengaruhi oleh faktor lain yang tidak diteliti.

\section{Kesimpulan dan Saran}

\section{Kesimpulan}

1. Terdapat perbedaan penggunaan Celebrity Endorser dan Typical-Person Endorser pada Iklan sampho Clear. Berdasarkan hasil uji t diperoleh t hitung sebesar 2,976 lebih besar dari t tabel 1,653.

2. Celebrity Endorser berpengaruh signifikan terhadap Brand Image shampoo merek Clear. Nilai t hitung sebesar 6,041 lebih besar dari t tabel 1,987.

3. Typical-Person Endorser berpengaruh signifikan terhadap Brand Image shampoo merek Clear. Nilai t hitung sebesar 3,417 lebih besar dari t tabel 1,987.

\section{Saran}

1. Penggunaan selebrity endorser secara signifikan berbeda dengan penggunaan tipycal-person endorser. Untuk itu disarankan kepada produsen produk shampoo Clear untuk menggunakan selebrity endorser untuk meningkatkan image merk produknya. Selebrity endorser yang digunakan sebaiknya selebrity yang terkenal dan mempunyai pengaruh terhadap publik.

2. Perusahaan shamphoo dapat menggunakan selebrity endorser dan tipycal-person endorser secara bersama-sama dalam mengiklankan satu merek produk agar lebih efektif dalam meningkatkan brand image. Hal ini dilakukan untuk mengantisipasi perbedaan persepsi perilaku konsumen terhadap model iklan yang menjadi endorser.

\section{DAFTAR PUSTAKA}

Aaker A David. 1999. Ekuaitas Merek. Edisi Indonesia. Jakarta : Mitra Utama.

Arikunto. 2002. Prosedur Penelitian Suatu Pendekatan Praktek. Jakarta : Rineka cipta

Basuswasta DH, dan T.H Handoko. 2000. Manajemen Pemasaran: Aplikasi Perilaku Konsumen, Edisi Pertama, Yogyakarta: BPFE Yogyakarta

Durianto, Darmadi, Sugiarto, \& Sitinjak, Tony. (2001). Strategi Menaklukkan Pasar Melalui Riset Ekuitas dan Perilaku Merek. Jakarta: PT. Gramedia Pustaka Utama.

Engel, James F., Blackwell, R. D., \& Miniard, P. W. (1990). Consumer Behavior. (6th ed.). International Edition, Forth Worth: The Dryden Press.

Ghozali, Iman. 2009. Aplikasi Analisis Multivariate dengan Program SPSS. Badan Penerbit Undip Semarang.Kotler, Philip. (2005). Manajemen Pemasaran, Jilid 1. (Edisi kesebelas). Klaten: PT. Indeks Kelompok Gramedia. 
dan Garry Amstrong. 2001. Prinsip-Prinsip Pemasaran, Edisi Kedelapan Jilid 2. Erlangga, Jakarta.

\& Keller, Kevin Lane. 2006. Marketing Management. 12th edition.. New Jersey : Prentice Hall

Monle, L dan Carla Johnson. 2004. Prinsip-prinsip Pokok Periklanan Dalam Perspektif Global. Prenada, Jakarta.

Peter, J.P. dan Jerry C. Olson. 2000. Consumer Behavior, Perilaku Konsumen dan Strategi Pemasaran, Edisi Empat Jilid 2. Erlangga, Jakarta.

Royan, Frans.M, 2005, Marketing Celebrities, Jilid I, Penerbit PT. Elex Media Komputindo, Jakarta.

Sebayang, Siahaan Simon, 2008, "Pengaruh Celebrity Endorser Terhadap Keputusan Pembelian Sepeda Motor Merek Yamaha Mio Pada Mio Automatik Club (MAC) Medan", Fakultas Ekonomi USU, Jurnal Manajemen Bisnis,Vol.1 No.3 Hal. 117125.

Shimp, Terence A. 2000/2003. Advertising Promotion and Supplement Aspect of Integrated Marketing Communication 5th Edition; Alih Bahasa : Periklanan Promosi dan Aspek Tambahan Komunikasi Pemasaran Terpadu, edisi ke-5, Terjemahan: Reyvani Syahrial. Jakarta : Erlangga

Sugiyono, 2006. Metode Penelitian Bisnis. Cetakan kesepuluh. Bandung : Alfabeta.

Supranto, J, (2001), Ekonmetrika, Jakarta

Suyanto, M. (2005). Strategi Perancangan Iklan televisi Perusahaan Top Dunia. Yogyakarta: Andi.

Temporal, Paul. (2001). Branding in Asia: Membangun Merek di Asia (Edisi terjemahan oleh Hari Suminto). Jakarta: PT. Interaksara.

Tjiptono, F. 2002. Strategi Pemasaran Edisi II. Andi Offset, Yogyakarta. 